\title{
DIAGNOSTIK KONSEPSI SISWA PADA MATERI SUHU DAN KALOR
}

\author{
W. Winarti ${ }^{1}$; I.S. Budiarti ${ }^{2)}$ \\ ${ }^{1)}$ Program Studi Pendidikan Fisika, UIN Sunan Kalijaga; winarti@uin-suka.ac.id \\ ${ }^{2)}$ Program Studi Pendidikan Fisika, Universitas Cenderawasih; indah_budiarti@yahoo.com
}

\begin{abstract}
Diagnostics in physics learning are carried out to find the level of students' conceptual understanding to the learning objectives. This study aimed to describe the conception of Madrasah Aliyah (MA) students in Special Region of Yogyakarta through diagnostic tests. Descriptive method was chosen to determine the level of students' conceptual understanding on chapter temperature and heat. The sampling technique used was stratified random sampling so that 365 students from class X Natural Sciences were positioned as samples. Test was chosen as data collecting technique using the developed Temperature and Heat Test Higher Order Thinking Skills (THT-HOTS) instrument. The results of the study were the level of conceptual understanding achievement of Madrasah Aliyah (MA) students in the Special Region of Yogyakarta on chapter temperature and heat. The conceptual understanding of students was classified in the low category. It could be seen from the percentage of conceptual understanding achievement in four sub-chapter, namely: temperature and thermometer, heat and black principle, changes in the form of substances and expansion, which value were less than $20 \%$.
\end{abstract}

Keywords: Diagnostics, conceptions, heat and temperature, THT-HOTS

\begin{abstract}
ABSTRAK
Diagnostik konsepsi pada pembelajaran fisika dilakukan untuk menemukan level pemahaman konsep siswa terhadap suatu materi. Tujuan penelitian ini adalah mendeskripsikan konsepsi siswa Madrasah Aliyah (MA) di Daerah Istimewa Yogyakarta melalui tes diagnostik. Metode deskriptif dipilih untuk mengetahui tingkat pemahaman siswa pada materi suhu dan kalor. Teknik penentuan sampel yang digunakan adalah teknik stratified random sampling, sehingga didapatkan sampel berjumlah 365 siswa dari kelas X IPA. Teknik pengumpulan data dilakukan melalui teknik tes dengan menggunakan instrumen tes Temperature and Heat Test Higher Order Thinking Skills (THT-HOTs). Hasil dari penelitian adalah level pencapaian konsepsi siswa Madrasah Aliyah (MA) di Daerah Istimewa Yogyakarta untuk materi suhu dan kalor. Pemahaman konsep siswa termasuk dalam kategori rendah. Hal ini ditunjukkan dari persentase pencapaian konsep pada empat sub materi, yaitu: suhu dan termometer, kalor dan asas black, perubahan wujud zat dan pemuaian, yang nilainya kurang dari $20 \%$.
\end{abstract}

Kata kunci: Diagnostik, konsepsi, suhu dan kalor, THT-HOTS

\section{PENDAHULUAN}

Pembahasan mengenai suhu dan kalor menjadi sangat penting, karena konsep suhu dan kalor ini banyak sekali terjadi pada fenomena sehari-hari yang ditemui di sekitar kita. Berdasarkan hasil pengamatan siswa dari fenomena yang terjadi itulah maka akan terbentuk konsepsi. Menurut Duit and Treagust (2012) konsepsi adalah intepretasi dan deskripsi yang terbentuk pada diri seseorang terhadap suatu objek atau fenomena yang ditemuinya. Konsepsi ini justru sudah dimiliki oleh siswa sebelum 
pembelajaran (Winarti et al., 2017). Jadi dapat dikatakan bahwa konsepsi merupakan tafsiran atau pemahaman sementara yang terbentuk saat siswa mengamati sesuatu yang akhirnya akan membentuk cara pandangnya terhadap objek atau fenomena.

Konsepsi awal yang terbentuk pada akhirnya akan mempengaruhi konsep-konsep selanjutnya terhadap materi yang terkait. Alwan (2011), menyatakan bahwa konsep awal siswa berkembang dari pengalamannya sehari hari, ketika siswa menemui suatu fenomena maka siswa akan berusaha merekonstruksi informasi dengan cara dan pemahamananya. Ketika konsep yang terbentuk itu sesuai dengan konsep ilmiah yang ilmiah yang benar maka pemahaman siswa akan semakin baik. Tetapi apabila proses rekonstruksi informasi tadi tidak sesuai dengan konsep ilmiah maka yang terjadi adalah munculnya miskonsepsi.

Fisika merupakan bagian dari sains yang mempelajari tentang fenomena alam dan proses yang ada didalamnya (Budiarti et al., 2020). Pelajaran fisika merupakan salah satu pelajaran yang sulit dipahami oleh siswa, sehingga penanaman konsep fisika di sekolah sangatlah penting (Budiarti, 2013). Konsep suhu dan kalor merupakan salah satu konsep dalam fisika. Konsep suhu dan kalor sudah diperoleh siswa sejak duduk di bangku sekolah dasar, sekolah menengah, sampai perguruan tinggi dalam kurikulum mata pelajaran IPA, khususnya fisika (Budiarti et al., 2017). Menurut Baser (2006), siswa mengalami kesulitan pada konsep perpindahan kalor secara konduksi yang terjadi pada selt belt yang terbuat dari logam dan non logam. Kecenderungan siswa untuk menghafalkan konsep perpindahan kalor tanpa disertai contoh konkrit, menyebabkan hasil belajar siswa menjadi rendah (Sisila and Siregar, 2017). Hal ini didukung oleh Sözbilir (2003), bahwa siswa mengalami kesulitan untuk mempelajari konsep suhu dan kalor karena konsep suhu dan kalor terlalu abstrak. Dengan demikian, konsepsi suhu dan kalor penting dipahami oleh siswa agar tidak menimbulkan miskonsepsi.

Penting bagi guru untuk merekonstruksi bagaimana siswa membangun konsep serta ide ilmiahnya dalam pembelajaran. Guru harus mengidentifikasi dan mendiagnostik konsepsi suhu dan kalor tersebut agar tidak menimbulkan kesalahan konsep yang berkepanjangan dan berujung pada miskonsepsi permanen yang sulit untuk diubah. Hal ini didukung oleh Budiarti (2017), bahwa pemahaman konsep fisika yang mendalam membuat siswa konsisten tentang kebenaran konsep yang diyakininya selama proses pembelajaran berlangsung. Dengan demikian, konsepsi fisika siswa tentang suhu dan kalor penting dideskripsikan, sehingga tujuan penelitian 
ini adalah mendeskripsikan konsepsi fisika siswa Madrasah Aliyah (MA) di Daerah Istimewa Yogyakarta pada materi suhu dan kalor.

\section{METODE PENELITIAN}

Jenis penelitian ini adalah deskriptif. Penelitian ini dilaksanakan di Daerah Istimewa Yogyakarta melibatkan Madrasah Aliyah dari 5 kabupaten, baik itu yang berstatus negeri maupun swasta. Teknik penentuan sampel yang digunakan dalam penelitian ini adalah teknik statified random sampling. Statified random sampling merupakan bagian teknik probability sampling yang merupakan suatu teknik yang digunakan bila populasi mempunyai anggota atau unsur yang tidak homogen dan berstrata. Siswa yang terlibat dalam penelitian ini sejumlah 365 siswa kelas X IPA.

Adapun teknik yang digunakan dalam pengumpulan data yakni dengan teknik tes dengan instrumen tes standar yang selanjutnya disebut sebagai Temperature and Heat Test Higher Order Thinking Skills (THT-HOTs). Instrumen THT-HOTS ini di adopsi dari instrumen standar yang dikembangkan oleh Winarti
(2017). THT-HOTS terdiri dari 20 soal pilihan ganda beralasan (two tier test). THT-HOTS ini merupakan serangkaian tes untuk mengukur HOTS dan pemahaman konsep siswa pada materi suhu dan kalor. THT-HOTS ini dibagi menjadi 4 sub konsep yakni suhu dan termometer, pemuaian, kalor dan asas black serta perubahan wujud zat.

Menurut (Mardapi, 2008) besarnya kemampuan seseorang dapat dilihat dari besarnya peluang menjawab benar dari sejumlah butir tes. Tingkat HOTS peserta didik dapat dihitung dengan menggunakan kategori berdasarkan rerata ideal dan simpangan baku ideal. Tingkat HOTS peserta didik dapat dihitung dengan menggunakan kategori berdasarkan rerata ideal dan simpangan baku ideal. Hal ini dilakukan dengan asusmsi bahwa kemampuan HOTS peserta didik pada matapelajaran fisika akan terdistribusi normal. Penentuan skor rata-rata ideal (Mi) dan skor simpangan baku ideal (SB) berdasarkan dari skor tertinggi dan terendah dari variabel. Adapun intepretasi dari kemampuan peserta didik dapat dilihat seperti Tabel 1:

Tabel 1. Intepretasi Kemampuan HOTS

\begin{tabular}{lcc}
\hline No & Interval Kemampuan & Level \\
\hline 1 & $M i+1,5 S B i<\theta$ & Sangat Tinggi \\
2 & $M i+0,5 S B i<\theta \leq M i+1,5 S b i$ & Tinggi \\
3 & $M i-0,5 S B i<\theta \leq M i+1,5 \mathrm{Sbi}$ & Sedang \\
4 & $M i-1,5 S B i<\theta \leq M i-0,5 S b i$ & Rendah \\
5 & $0<M i-0,5 S b i$ & Sangat Rendah \\
\hline
\end{tabular}


Mean Ideal $(M i)$ adalah rerata ideal dan SBi merupakan simpangan baku ideal. Mean Ideal dihitung dengan $M i=\frac{1}{2}\left(X_{t}-X_{r}\right)$ dan $S_{B i}=\frac{1}{6}\left(X_{t}-X_{r}\right)$, $X_{t}$ merupakan skor maksimal ideal dan $X_{r}$ merupakan skor minimal ideal. Hal ini dilakukan dengan asusmsi bahwa kemampuan HOTS peserta didik pada matapelajaran fisika akan terdistribusi normal. Intepretasi jawaban peserta didik dilakukan atas dasar politomus dengan 5 kategori dan hasil pengukuran. Langkah selanjutnya adalah melakukan estimasi kemampuan. Setiap pengukuran melibatkan parameter butir dan parameter kemampuan. Parameter butir akan menunjukkan karakteristik dari suatu tes, sedangkan parameter kemampuan adalah besaran yang akan diestimasi. Apabila besarnya parameter butir diketahui, maka estimasinya dapat diketahui dengan mudah.

Agar dapat digunakan, suatu tes juga perlu dilengkapi dengan pedoman penskoran. Pedoman penskoran dirancang untuk menjaga objektivitas penilaian dan kepastian skor yang diperoleh peserta tes. Penskoran ini dibuat dalam 5 kategori dengan ketentuan masing-masing kategori seperti pada Tabel 2:

Tabel 2. Kategori Penskoran

\begin{tabular}{|l|l|}
\hline Kategori 0 & $\begin{array}{l}\text { Jika siswa salah dalam menjawab Pilihan Ganda } \\
\text { (PG), tidak menuliskan alasan jawaban dan } \\
\text { memilih tidak yakin pada Tingkat Keyakinan } \\
\text { (TKY). }\end{array}$ \\
\hline Kategori 1 & $\begin{array}{l}\text { a) Jika siswa salah dalam menjawab PG, salah } \\
\text { menjawab alasan dan memilih tidak yakin. } \\
\text { b) Jika salah menjawab PG salah alasan jawaban } \\
\text { dan yakin pada TKY. } \\
\text { c) Jika Benar menjawab PG, tanpa alasan dan } \\
\text { yakin pada TKY. }\end{array}$ \\
\hline Kategori 2 & $\begin{array}{l}\text { a) Jika siswa benar menjawab PG, salah alasan } \\
\text { jawaban dan tidak yakin pada TKY. }\end{array}$ \\
& b) Jika siswa salah menjawab PG, benar alasan \\
jawaban dan yakin pada TKY.
\end{tabular}


Model penskoran ini dibuat untuk menghindari penskoran yang dilakukan dengan hanya memberi 2 kategori saja yakni benar dan salah saja (dikotomus). Pada penelitian ini model penskoran politomus bertujuan untuk menemukan adanya kasus-kasus kesalahan konsep pada siswa (DeMars, 2010; Isgiyanto, 2011).

\section{HASIL DAN PEMBAHASAN}

Temuan

penelitian

ini mengalami banyak masalah, sehingga siswa mengalami beberapa kasus miskonsepsi. Berdasarkan hasil penelitian yang telah dilakukan, hasil analisis data persentase konsepsi siswa pada penelitian ini memiliki pola pencapaian level yang berbeda. Hasil untuk tiap kategori persentase konsepsi ditunjukkan pada Tabel 3:

mengungkapkan bahwa ada banyak masalah pada pemahaman konsep, siswa

Tabel 3. Persentase Konsepsi Siswa pada Materi Suhu dan Kalor

\begin{tabular}{|c|l|c|c|c|c|c|}
\hline \multirow{2}{*}{ No } & \multicolumn{5}{|c|}{ Materi } & \multicolumn{5}{|c|}{ Persentase (\%) } \\
\cline { 3 - 7 } & & $\begin{array}{c}\text { Kategori } \\
\mathbf{0}\end{array}$ & $\begin{array}{c}\text { Kategori } \\
\mathbf{1}\end{array}$ & $\begin{array}{c}\text { Kategori } \\
\mathbf{2}\end{array}$ & $\begin{array}{c}\text { Kategori } \\
\mathbf{3}\end{array}$ & $\begin{array}{c}\text { Kategori } \\
\mathbf{4}\end{array}$ \\
\hline 1 & Kalor dan Asas Black & 18,6 & 15,3 & 34,8 & 23,4 & 7,9 \\
\hline 2 & Pemuaian & 17,5 & 19,4 & 31,1 & 24,1 & 7,9 \\
\hline 3 & Perubahan Wujud Zat & 11,3 & 27,2 & 23,1 & 27,7 & 10,7 \\
\hline 4 & Suhu dan Termometer & 4,1 & 18,4 & 26,5 & 35,8 & 15,2 \\
\hline
\end{tabular}

Tabel 3 menunjukkan setiap kategori jawaban siswa berdasarkan konsep-konsep yang mereka pelajari di setiap sub materi. Sesuai dengan kriteria penskoran yang sudah ditetapkan, maka setiap sub materi dilakukan pengkategorian yakni $0,1,2,3$ dan 4 . Berdasarkan nilai kategori tersebut, dapat diketahui konsepsi mayoritas pada siswa untuk setiap sub materinya. Kategori 4 merupakan kategori jawaban terbaik, yakni apabila siswa benar saat menjawab pilihan ganda, benar saat menjawab alas an, dan menyatakan yakin pada tingkat keyakinan. Namun, jika dilihat dari Tabel 3, persentase kategori 4 justru yang paling rendah dibandingkan dengan 4 kategori lainnya. Kategori 3 memperlihatkan angka rata-rata yang cukup besar pada setiap materinya yakni ada di 23,4 untuk materi kalor dan asas black, 24,1 untuk pemuaian, 27,7 untuk konsep perubahan wujud zat dan 35,8 untuk suhu dan termometer. Kategori skor 3 merupakan kategori yang mengakomodir banyak kemungkinan jawaban siswa, yakni; (a) jika siswa benar saat menjawab 
pilihan ganda, jika siswa memberikan jawaban "tidak yakin" pada pertanyaan tingkat keyakinan, (b) jika siswa benar saat menjawab pilihan ganda, namun salah dalam menjawab alasan jawaban, dan menyatakan "yakin" pada tingkat keyakinan, dan (c) jika siswa salah saat menjawab pilihan ganda, benar saat menjawab alasan jawaban dan menyatakan “yakin" pada tingkat keyakinan untuk setiap tingkatan soal yang mereka kerjakan.

Berdasarkan hasil data yang terlihat pada Tabel 3, hasil menunjukkan bahwa pemahaman konsep siswa pada materi suhu dan kalor memang masih rendah. Hal ini sekaligus menunjukkan adanya permasaahan dalam pemahaman konsep siswa. Temuan ini senada dengan beberapa temuan lain. Pada penelitian sebelumnya, ada yang telah mengidentifikasi kasus miskonsepsi siswa. Hasil yang didapatkan dari penelitian tersebut menyatakan bahwa 87\% dari sampel siswa Sekolah Menengah Atas ternyata mengalami masalah pada konsep-konsep kalor (Başer, 2006). Begitu halnya dengan penelitian Arnold and Millar (1994) yang menyatakan bahwa pemahaman peserta didik tentang konsep fisika, khususnya tentang suhu dan kalor, berasal dari pengalaman yang mereka dapatkan dari kehidupan sehari-hari. Konsep yang berkaitan dengan suhu dan kalor secara langsung berhubungan dengan lingkungan fisik organisme hidup yang mengalami kenaikan atau penurunan suhu di hidupnya.

Analisis selanjutnya adalah menentukan pada konsep mana saja siswa mengalami permasalahan dalam pemahaman konsep-konsep suhu dan kalor. Hasil dari analisis ini disajikan pada Gambar 1:

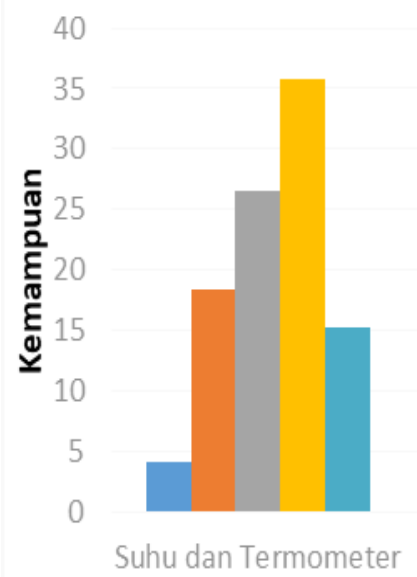

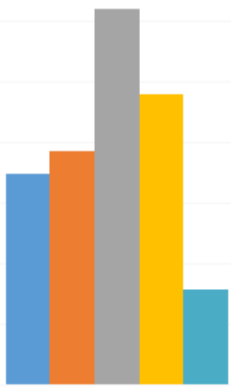
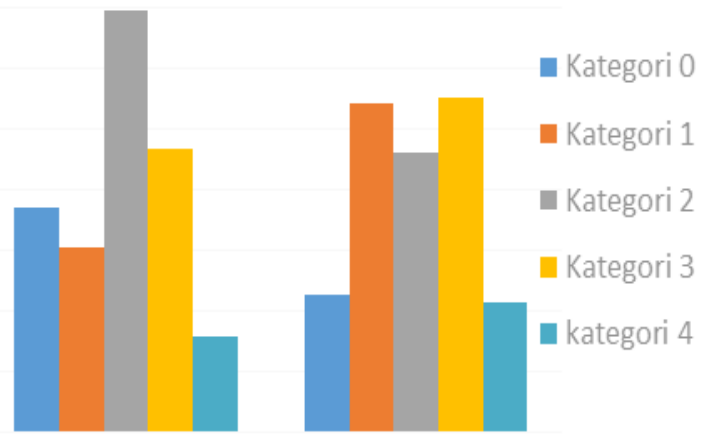

Pemuaian

Kalor dan Azas Black Perubahan Wujud Zat Aspek Materi

Gambar 1. Grafik Konsepsi Siswa pada Materi Suhu dan Kalor 
Berdasarkan grafik pada Gambar 1, tampak bahwa kategori 4 untuk semua konsep berada pada skor yang lebih rendah dibandingkan dengan kategori lainnya. Konsep pemuaian dan konsep kalor serta konsep Asas Black memiliki nilai rata-rata masing-masing sebesar 7,9. Nilai tersebut menunjukkan bahwa pemahaman siswa sangat rendah untuk kedua konsep tersebut dibandingkan dengan konsep-konsep yang lain pada materi suhu dan kalor.

Soal di bawah ini merupakan contoh soal konsep Asas Black yang digunakan untuk mengetahui konsepsi siswa. Siswa menjawab dengan menghubungkan suhu kedua gelas yang berisi es tersebut dengan logika mereka. Gambar 2 menunjukkan salah satu soal yang merepresentasikan kegiatan ini.

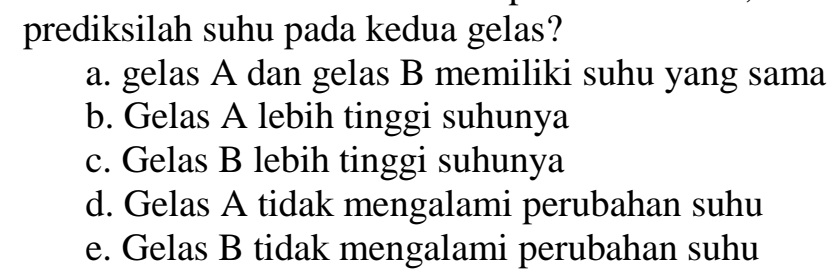

Gambar 2. Contoh Soal untuk Konsep Kalor dan Asas Black

Gambar 2 menunjukan sebuah soal yang menuntut pemahaman konsep siswa tentang Asas Black. Pada soal tersebut, siswa dituntut untuk dapat memprediksi suhu setelah terjadi pencampuran kedua gelas es dengan massa yang berbeda. Adapun respons siswa terhadap pertanyaan tersebut seperti terlihat pada Gambar 3.

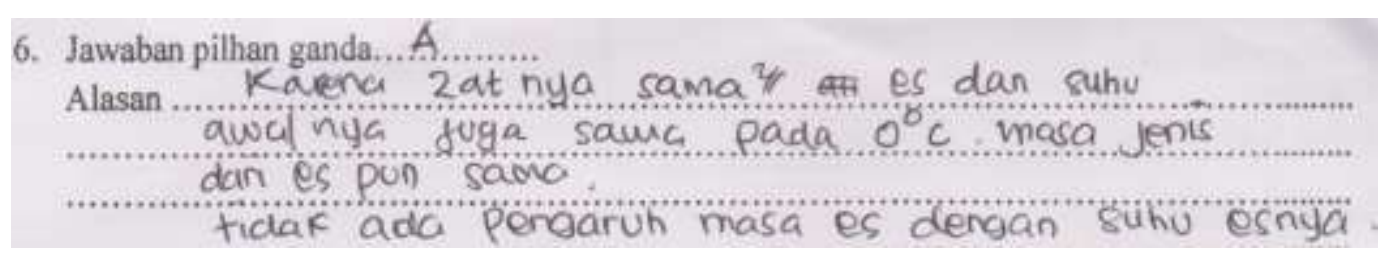

Gambar 3. Salah satu jawaban siswa untuk soal asas black

Gambar 3 memperlihatkan alasan siswa merujuk pada analisis ketika zatnya sama dan zatnya memiliki suhu awal yang sama, yakni $0^{\circ} \mathrm{C}$. Oleh karena itu, peserta didik berpikir suhu akhirnya sama karena diletakkan di tempat yang memiliki suhu sama. Sebagian besar peserta didik dari berbagai MA menjawab pilihan A, yakni suhu akhirnya adalah sama. Hal tersebut menunjukkan bahwa pemahaman siswa yang masih lemah. Setelah dilakukan pendalaman jawaban, diperoleh analisis 
berikut: siswa beranggapan bahwa ketika zat memiliki suhu yang sama, maka tidak akan terjadi perubahan suhu pada zat meskipun zat ditempatkan pada suhu lingkungan yang sama. Siswa kurang memahami makna dari persamaan yang mendukung pada persamaan kalor yang ada di dalam Fisika, yaitu:

$$
\begin{aligned}
& Q=m c \Delta T \\
& \Delta T=\frac{Q}{m c}
\end{aligned}
$$

Jika dilihat dari persamaan tersebut, maka dapat diketahui ada faktor $Q$ sebagai kalor atau perubahan kalor dan massa $m$ dari masing-masing zat yang ada (dalam hal ini adalah 100 gram dan 5 gram) kedua zat tersebut berbeda massa. Sedangkan $c$ dari kedua benda sama karena zatnya sama.

Analisis pada butir soal pada Gambar 3 dapat juga melalui pemisalan dua gelas identik yang suhu awalnya sama sebelum diisi es, yaitu sama dengan suhu ruang. Ketika es dimasukkan ke dalam gelas suhu gelas berubah, dan nilainya tidak sama karena jumlah es berbeda (dan signifikan bedanya) sehingga ketika dimasukkan ke dalam oven kedua gelas dalam kondisi suhu awal yang berbeda. Ketika berada dalam oven (dalam kondisi panas tentunya) hanya dalam beberapa saat saja (sebagaimana disebutkan dalam soal) kalor yang masuk dalam gelas (dan es) belum cukup untuk membuat suhu kedua gelas sama. Untuk es, penyimpanan dalam oven beberapa saat mungkin sudah mencairkan 5 gram es, tetapi hanya membuat sebagian kecil dari 100 gram es mencair. Suhu keduanya berbeda.

Kemampuan siswa dalam memahami makna fisis dari persamaan (rumus) menjadi sangat penting untuk penguasaan konsep fisika. Sebenarnya, dengan melihat hubungan persamaan di atas, maka dapat disimpulkan bahwa $\Delta T \approx \frac{1}{m}$.

Berdasarkan soal tersebut, diketahui bahwa kedua zat sama yakni es dan tentunya $c$-nya akan sama. Es tersebut diletakan di dalam oven yang sama. Artinya, suhu lingkungan yang memengaruhi adalah sama besar dan kalor $Q$ yang akan memengaruhi/diterima juga sama. Hal ini sesuai dengan prinsip pertukaran kalor dan hukum kekekalan energi $(Q a=Q b)$. Dari pernyataan tersebut, dapat dikatakan bahwa $Q=$ konstan. Selain itu, waktu yang diberikan kepada dua zat tersebut adalah sama $T a=T b$. Maka, satu-satunya variabel yang memengaruhi adalah massa dari kedua zat. Dari persamaan $\Delta T \approx \frac{1}{m}$, dapat disimpulkan bahwa perubahan suhu berbanding terbalik dengan massa benda. Ada pemahaman yang keliru dari banyak peserta didik yang menjawab salah pada soal tersebut. Untuk mengetahui lebih rinci dimana letak kekeliruan siswa pada konsep tersebut maka dilakukan pendalaman dengan 
wawancara dan memberi kasus lain dan analogi yang berbeda dengan konsep yang sama. Berdasarkan upaya pendalaman analisis, diperoleh kesimpulan bahwa terjadi kekeliruan dalam pemahaman peserta didik terhadap konteks perubahan suhu dan suhu pada benda. Siswa cenderung menyamakan kedua konsep tersebut.

Kesalahan konsep yang sama juga terjadi di beberapa penelitian terdahulu dari beberapa studi yang dilakukan Turgut and Gurbuz (2011), Kiong et al. (2012), dan Alwan (2011). Ketiga penelitian tersebut menemukan bahwa miskonsepsi permanen terjadi pada siswa yang memiliki konsepsi bahwa perubahan suhu bergantung kepada massa dari benda. Sama halnya dengan temuan pada penelitian ini. Siswa diberikan analisis masalah untuk benda yang sama dengan ukuran berbeda. Ternyata, konsepsi siswa merujuk pada adanya pengaruh ukuran benda terhadap suhu akhirnya.

Pemahaman siswa tentang konsep suhu banyak dipengaruhi oleh pengalaman pribadi yang ditemui dalam kehidupan sehari-hari, dimana pengetahuan berdasarkan pengalaman itu pada akhirnya akan membentuk konsepsi siswa. Sebagian besar siswa dapat menjawab benar pada soal pilihan ganda, tetapi alasan yang disampaikan tidak mendukung dan kurang tepat. Kesulitan sebagian besar siswa adalah mengemukakan alasan yang mendasari fenomena atau soal suhu dan kalor. Siswa menjawab hanya berdasarkan naluri saja, di mana sebenarnya jawaban tersebut logis, tetapi belum sesuai dengan konsep yang benar. Hal ini sejalan pula dengan temuan penelitian yang dilakukan oleh Tanahoung et al., (2010) dan Zoller and Tsaparlis (1997) yang menyatakan bahwa kegagalan siswa dalam membangun konsep tentang kerangka kerja logis dari suatu gejala fisika dan menghubungkan dengan konsep yang relevan sering menghasilkan konsepsi siswa yang tidak konsisten dengan konsep ilmiah (scientific ideas), bahkan cenderung akan membentuk alternatif konsepsi atau kasus-kasus miskonsepsi.

Sampel siswa di semua sekolah merupakan siswa yang telah terlibat dan mendapatkan pembelajaran mengenai konsep-konsep pada materi suhu dan kalor di kelas $X$, sehingga pengetahuan siswa merupakan gabungan dari pemahaman di jenjang sebelumnya (pengetahuan yang diperoleh di SMP/MTs) dan pembelajaran yang dilakukan sebelum tes diagnostik berlangsung. Proses pembelajaran pada materi suhu dan kalor menggunakan pendekatan teacher centered learning (TCL) dengan metode ceramah. Pendidik di instansi pendidikan yang menjadi sampel pada penelitian ini belum berupaya menggunakan pendekatan, model, dan metode yang lain yang lebih kompleks dan inovatif untuk meningkatkan pemahaman 
konsep siswa, sehingga level konsepsi siswa masih rendah.

\section{SIMPULAN DAN SARAN \\ SIMPULAN}

Konsepsi siswa Madrasah Aliyah (MA) di Daerah Istimewa Yogyakarta untuk materi suhu dan kalor masih masuk dalam kategori rendah. Hal ini ditunjukkan dari persentase kategori 4 untuk konsep suhu dan termometer, kalor dan asas black, perubahan wujud zat dan pemuaian, masing-masing adalah 15,$2 ; 7,9 ; 10,7$; dan 7,9. Melalui penelitian ini, terungkap pula bahwa konsepsi siswa pada materi suhu dan kalor paling rendah pada konsep kalor dan Asas Black serta pemuaian.

\section{SARAN}

Pembelajaran suhu dan kalor sebaiknya berbasis kontekstual, sehingga siswa mampu merekonstruksi konsep secara benar melalui fenomena yang ditemui dalam kehidupan sehari-hari. serta mendukung Higher Order Thinking Skills (HOTs) agar konsepsi siswa tentang suhu dan kalor konsisten kebenarannya.

\section{UCAPAN TERIMAKASIH}

Terimakasih kepada UIN Sunan Kalijaga dan Program Studi Pendidikan Fisika yg telah memfasilitasi penelitian ini sampai dengan selesai.Tak lupa peneliti haturkan terimakasih sebesar besarnya kepasa semua Guru Fisika MA DIY yang telah membantu dan sangat berkontribusi dalam penelitian ini

\section{DAFTAR PUSTAKA}

Alwan, A. A. (2011). Misconception of heat and temperature among physics students. Procedia-Social and Behavioral Sciences, 12, 600-614;

Arnold, M., \& Millar, R. (1994). Children's and lay adults' views about thermal equilibrium. International Journal of Science Education, 16(4), 405-419;

Başer, M. (2006). Fostering conceptual change by cognitive conflict based instruction on students' understanding of heat and temperature concepts. Eurasia Journal of Mathematics, Science and Technology Education, 2(2), 96-114;

Budiarti, I. S., Lumbu, A., \& Sulistiowati, D. W. I. (2013). Pengaruh Pendekatan Konstruktivisme Terhadap Hasil Belajar Siswa Kelas Viii Smp Negeri 11 Jayapurapada Pokokbahasan Getaran Dan Gelombangtahun Ajaran 2012/2013. Jurnal Ilmu Pendidikan Indonesia, 1(2), 53-62;

Budiarti, I S, Suparmi, A., Sarwanto, S., \& Harjana, H. (2020). Effectiveness of Generation, Evaluation, and Modification - Cooperative Learning (Gem-Cl) Model Selaras Bakar Batu Cultural Practice in Papua. Jurnal Pendidikan IPA Indonesia, 9(1);

Budiarti, Indah Slamet. (2017). Potensi budaya bakar batu dalam pembelajaran fisika. Prosiding SNPF (Seminar Nasional Pendidikan Fisika), 22-25;

Budiarti, Indah Slamet, Suparmi, Sarwanto, \& Harjana. (2017). Students' conceptual understanding consistency of heat and temperature. Journal of Physics: Conf. Series, 795, 012051. https://doi.org/10.1088/1742-6596/75 5/1/011001; 
DeMars, C. (2010). Item response theory. Oxford University Press;

Duit, R., \& Treagust, D. F. (2012). How can conceptual change contribute to theory and practice in science education? In Second international handbook of science education (pp. 107-118). Springer;

Isgiyanto, A. (2011). Diagnosis kesalahan siswa berbasis penskoran politomus model partial credit pada matematika. Jurnal Penelitian Dan Evaluasi Pendidikan, 15(2), 308-325;

Kiong, T. T., Yunos, J. M., Heong, Y. M., Hussein, A. H., \& Mohamad, M. M. (2012). Thinking skills for secondary school students in Malaysia. Journal of Research, Policy \& Practice of Teachers \& Teacher Education (JRPPTTE), 2(2), 12-23;

Mardapi, D. (2008). Teknik penyusunan instrumen tes dan nontes. Yogyakarta: Mitra Cendikia Press;

Sisila, A., \& Siregar, T. (2017). Pengaruh Penggunaan Media Kit IPA Terhadap Motivasi Dan Hasil Belajar Siswa Pada Materi Hantaran Panas Pada Benda Kelas VI Sekolah Dasar Negeri 03 Nabire. Jurnal Ilmu Pendidikan Indonesia, 5(1), 1-13;

Sözbilir, M. (2003). A review of selected literature on students' misconceptions of heat and temperature. Bogazici Universitesi Egitim Dergizi, 20(1), 25-41;
Tanahoung, C., Chitaree, R., \& Soankwan, C. (2010). Probing Thai freshmen science students' conceptions of heat and temperature using open-ended questions: A case study. Eurasian Journal of Physics and Chemistry Education, 2(2), 82-94;

Turgut, Ü., \& Gurbuz, F. (2011). Effects of Teaching with 5e Model on Students' Behaviors and Their Conceptual Changes about the Subject of Heat and Temperature. International Online Journal of Educational Sciences, 3(2);

Winarti, C., Cari, A., Suparmi, I., Budiarti, J., Handhika, H., \& Viyanti, V. (2017). Identification of consistency and conceptual understanding of the Black principle. Ideas for 21st Century Education, 2004, 249-252. https://doi.org/10.1201/97813151665 75-50;

Zoller, U., \& Tsaparlis, G. (1997). Higher and lower-order cognitive skills: The case of chemistry. Research in Science Education, 27(1), 117-130. 